Hernán Corral Talciani - El embrión humano: del estatuto antropológico al...

\title{
EL EMBRIÓN HUMANO: DEL ESTATUTO ANTROPOLÓGICO AL ESTATUTO JURÍDICO
}

\author{
Hernán Corral Talciani \\ Profesor de Derecho Civil en la \\ Universidad de los Andes
}

\author{
"Hominum causa omne ius constitutum sit" \\ Hermogeniano, Digesto 1.5.2. \\ "In questo mondo gli altri siamo noi" \\ Umberto Tozzi, Le mie canzioni (CD 1991)
}

\section{Una cuestión a la vez vieja y actual}

La consideración jurídica del nasciturus o criatura humana concebida pero aún no nacida es una vieja cuestión que preocupó ya a los juristas romanos. Se plantearon ellos qué protección jurídica debe concederse a este ser, que no tiene apariencia visible, que no ha sido presentado en sociedad, que no tiene nombre, cuya existencia se presenta frágil, difuminada y esencialmente dependiente. El desconocimiento del proceso de reproducción inducía a pensar que la criatura concebida pero no nacida consistía en una cierta especie de órgano de la mujer, cuya falta de autonomía implicaba la imposibilidad de reconocerle como titular o sujeto de relaciones jurídicas.

Pero por otro lado, la situación - de no escasa ocurrencia- de que un niño terminara naciendo después de la muerte de su padre, (la filiación póstuma), determinaba que no se pudiera mantener la coherencia de ese planteamiento, sin incurrir en una grave injusticia. Si se afirmaba que sólo al nacer el niño podía adquirir derechos para sí, se desconocía la existencia de ese hijo aun antes de la muerte de su padre y, por tanto, con capacidad para ser su heredero.

Como se ve, el problema se centraba no tanto en la personalidad del concebido, sino más bien en su capacidad para ser titular de derechos patrimoniales.

En nuestra época la cuestión se actualiza por otros caminos. Al reafirmarse los derechos individuales de la mujer se comienza a apreciar como una carga -a veces intolerable- el proceso de gestación o embarazo, y se percibe la interrupción de ese embarazo (con la consecuente muerte del feto) como un derecho o libertad fundamental de toda mujer. El problema de la legalización del aborto ha reencendido la 
cuestión del status jurídico del embrión, aunque ahora lo discutido no es su capacidad patrimonial, sino su derecho a nacer y a vivir.

Conjuntamente hacen su aparición los avances de la ingeniería genética y los procedimientos biotecnológicos aplicados a la reproducción humana, que plantean el problema de la utilización y manipulación de embriones concebidos extracórporeamente. Desde que en 1978 se anunciara al mundo el nacimiento del primer niño concebido in vitro, el panorama de la aplicación de las tecnologías biológicas y genéticas al problema de la reproducción humana ha puesto en el tapete la admisibilidad de la utilización de embriones humanos. Se ponen en práctica procedimientos como el desecho de embriones sobrantes o "supernumerarios", su criopreservación o congelamiento, su "donación" o intercambio; su explotación para el tratamiento de enfermedades de adultos, la manipulación de su código genético, su división o clonación, etc.

Cuando se observa este campo de actividades, todas de ellas justificadas sobre la base de tender a la realización de fines loables (superar la esterilidad, desarrollar el conocimiento científico, sanar enfermedades incurables, prevenir anomalías genéticas), la sociedad, y sobre todo los juristas, comienzan a interrogarse cada vez con mayor intensidad si la condición jurídica de estas criaturas humanas permite estimar ética y justa su destrucción, utilización o manipulación en aras de la obtención de finalidades ajenas a sus propios intereses.

Planteado el problema, nos detendremos primeramente en analizar cómo se enfrentó la primera cuestión relacionada con la titularidad patrimonial del nasciturus. para luego ocuparnos de sus derechos personales.

\section{El problema de la titularidad patrimonial}

Como decíamos, los juristas romanos afirmaron que la capacidad patrimonial podía sólo comenzar con el nacimiento, cuando la criatura se hacía visible y adquiría vida independiente de la madre. Antes, el feto, según la opinión más común, es considerado como una mulieris portio vel viscerum (Ulpiano, D. 25.4.11), sin individualidad ni patrimonio propio. No obstante, su fina prudencia los indujo a ofrecer criterios y reglas que permitían atribuir derechos patrimoniales, sobre todo sucesorios, al nasciturus en ciertas situaciones específicamente determinadas en los textos, derechos que se hacían efectivos una vez nacido el niño.

Con estos textos del Corpus luris, los glosadores y comentaristas del Derecho común construyeron una máxima que adquiriría luego valor universal: el aforismo conceptus pro iam nato habetur quotiens de eius commodi agitur; con el cual se expresa el criterio de que al concebido se le considera como nacido para todos los efectos jurídicos que vayan en su provecho ${ }^{1}$.

\footnotetext{
${ }^{1}$ Cfr. VOLTERRA, EDUARDO, Instituciones de Derecho Privado, Civitas, Madrid, reimp. 1991, pp. 75-76. Nuestro romanista GUZMAN BRITO, ALEJANDRO, Derecho Privado Romano, Edit. Jurídica de Chile, Santiago, 1996, t. I, § 54, pp. 276-277, sostiene, sin embargo, que la regla estaba ya sentada por la jurisprudencia romana, por lo que debe aceptarse que el sistema romano considera al nasciturus como sujeto del derecho. En su opinión la expresión de Ulpiano de que el embrión no es más que una parte de la mujer, no tiene alcance general ni pretende describir la realidad biológica del que está por nacer.
} 
La regla tuvo gran fortuna pues hasta el día de hoy es consagrada expresamente por un buen número de legislaciones. Los Códigos Civiles de Portugal (art. 66.2.4ำ CC), Italia (art. 1 CC), Suiza (art. 31.2 CC), Guatemala (art. 1 CC), Ecuador (art. 69 CC), Brasil (art. 4 CC) y Chile (art. 75 CC), la consagran mediante una especial reserva de derechos que beneficia al no nacido. Otros cuerpos jurídicos, como el Código Civil Francés y el Código Alemán (B.G.B.), prefieren disponer expresamente la protección de los derechos del no nacido para ciertos efectos particulares (filiación, sucesión. alimentos, etc.), pero la doctrina y la jurisprudencia entienden que estas disposiciones son expresiones particulares de la regla general que considera al hijo como nacido para todo lo que vaya en su interés.

Siendo esta solución pacíficamente admitida, la controversia se ha volcado a explicar dogmáticamente esta protección especial del nasciturus, y a tratar de hacerla compatible con el criterio de que el nacimiento determina la personalidad y el inicio de la capacidad patrimonial. Grandes esfuerzos se han desplegado para intentar exponer de modo satisfactorio cuál es la naturaleza jurídica de la protección civil del concebido, surgiendo las más diversas teorías. A continuación damos cuenta de las principales²:

\section{a ) El concebido como persona anticipada}

Una explicación que parece ser bastante coherente es la de afirmar que es la concepción la que determina la personalidad y no el nacimiento. Al no nacido se le reconocen derechos porque, siendo persona tiene ya la aptitud para adquirirlos. Esta postura ha tenido incluso acogida legislativa. El Código Civil argentino, (1871), afirma que "desde la concepción en el seno materno comienza la existencia de las personas, y antes de su nacimiento pueden adquirir derechos, como si ya hubiesen nacido" (art. 70 ). Por su parte, el actual art. 16 del Código Civil francés (modificado por la ley № 94-653, de 2 de julio de 1994) dispone que "la ley asegura el primado de la persona, prohibe todo atentado a la dignidad de aquella y garantiza el respeto del ser humano desde el comienzo de su vida".

El inconveniente técnico que presenta esta teoría estriba en justificar por qué entonces, si el feto es persona, se le niega esa titularidad cuando su muerte se produce antes del nacimiento. De allí que algunos hablen de personalidad anticipada, condicional o futura, sin caer en la cuenta que el concepto de personalidad es incompatible con ese tipo de matizaciones.

\section{b) El concebido como titular con capacidad limitada}

En otras formulaciones teóricas se pretende diferenciar los conceptos de personalidad y de capacidad, de modo que el nasciturus no podría considerarse persona, pero bien podría gozar de una cierta capacidad, siquiera limitada, parcial y revocable. Nuevamente, no es fácil concordar esta explicación con el concepto de capacidad general de goce que presupone la ausencia de restricciones.

c) El concebido como futuro beneficiario de derechos sin sujeto actual

Para otras opiniones, la cuestión se resuelve echando mano de la teoría de los derechos sin sujeto, que justamente sostiene la existencia de bienes o derechos

\footnotetext{
" Para un análisis más detallado, puede verse nuestro trabajo "Comienzo de la existencia y personalidad del que está por nacer".
} en Revista de Derecho de la Universidad Católica de Valparaíso, XIII (1989-1990), pp. 41 y ss. 
patrimoniales que pueden configurarse sin la necesidad de un titular actual. Los derechos que se defieren a la criatura no nacida serían de este tipo, de manera que se mantienen en suspenso en espera de un titular que todavía no tiene existencia legal. En Chile sostiene esta explicación GONZALO FIGUEROA ${ }^{3}$.

d) El concebido como beneficiario de una ficción de nacimiento

Otra explicación que se ha ofrecido para solucionar la cuestión es la que sostiene que estamos frente a un nuevo caso en que el Derecho utiliza el medio técnico de la "ficción" para lograr un resultado, que se aprecia como necesario y justo, sacrificando así la coherencia de los principios en aras de conseguir una mayor adecuación a la realidad social. Entre nosotros, el gran tratadista CLARO SOLAR escribe que en este caso la ley forja una ficción de que el concebido ha nacido antes de que ocurriera efectivamente ese hecho ${ }^{4}$

\section{e) El concebido como persona jurídica técnica}

También se ha pretendido encuadrar la situación del nasciturus dentro del concepto de "persona jurídica", y se ha sostenido (en la doctrina alemana) que el embrión y su patrimonio eventual constituirían una forma de persona jurídica técnica o tácita, que se sumaría a las reguladas expresamente por la ley como las corporaciones, fundaciones y sociedades.

Ante esta multiplicidad de construcciones dogmáticas, no faltan finalmente quienes estiman más sincero reconocer que "el asunto no tiene una explicación satisfactoria" $1{ }^{5}$.

En todo caso, como vemos, la cuestión práctica está resuelta: el nasciturus puede adquirir derechos patrimoniales; lo que se discute es sólo como lo explicamos desde el punto de vista de la teoría jurídica. La cosa resulta más compleja cuando observamos el problema de la titularidad sobre derechos personales.

\section{El embrión humano y sus derechos personales}

\section{Los descubrimientos de la biología reproductiva: vida humana o vida personalizada}

La misma fecundación in vitro y los descubrimientos en materia de reproducción humana y genética, han puesto paradojalmente de relieve cómo el óvulo femenino fecundado por el espermio masculino es un organismo que desde la unión de esos gametos posee un principio vital que determina y dirige su propio desarrollo, sin necesidad de intervenciones externas. Se ha observado que el huevo fecundado, estando incluso fuera del seno materno, comienza a dividirse y a crecer, controlando él mismo su devenir biológico.

\footnotetext{
${ }^{3}$ FIGUEROA YAÑEZ, GONZALO, El parimonio, Edit. Jurídica de Chile, Santiago, 1991, N² 217, p. 416. En un sentido similar, LYON PUELMA, ALBERTO, reora de la personalidad, Ediciones Universidad Católica de Chile, Santiago, 1993, pp. 45-46, postula que la ley suspende "la radicación o atribución inmediata en una determinada persona de dichos bienes en espera que el titular futuro que no existe, pero que se espera que exista, nazca y sea persona".

${ }^{4}$ CLARO SOLAR, LUIS, Explicaciones de oerecho ciul chileno y comparado , Imprenta El Imparcial, 1942, t. I, № 416, p. 223.

${ }^{5}$ VODANOVIC. ANTONIO, aurso de perecho dili. parie seneral y los sujetos de verecho, Nascimento, Santiago, p. 164
} 
Se ha generado así un amplio consenso en el sentido de que la vida humana, descle el punto de vista biológico, tiene su inicio en este proceso que llamamos concepción, esto es, en la unión de los gametos para la formación de una nueva célula: el cigoto.

Pero las discrepancias comienzan a manifestarse cuando se pretende elucidar si la vida que se origina en la fecundación es una vida humana individual y personalizada o no. La cuestión no es baladí: si se afirma que con la concepción comienza la "vida humana" pero no necesariamente un nuevo individuo o persona, es posible sostener que en esta etapa previa ese organismo, aun no personalizado, puede ser utilizado para satisfacer intereses diversos a los de su propio bienestar. En caso contrario, la dignidad e inviolabilidad de la personalidad humana brindarían protección al huevo desde la misma fecundación, haciendo ética y jurídicamente reprochables todas las intervenciones tecnológicas que lo supeditaran a la satisfacción de aspiraciones de terceros.

La discusión intelectual se ha visto de algún modo perturbada por los fuertes intereses prácticos que existen para que las legislaciones y orientaciones internacionales no prohiban ni sancionen las formas de utilización de embriones y, sobre todo, por la consagración legal en un gran número de naciones de la posibilidad de la mujer de poner fin a la vida del feto que porta en su seno.

\section{Una fórmula de compromiso: el concepto de pre-embrión}

En un intento por ofrecer una explicación teórica a la posibilidad de disponer de huevos fecundados y embriones de corto tiempo, se forja el concepto de "pre-embrión", hasta hace pocos años absolutamente ignorado por los tratados científicos ${ }^{6}$. Esta categoría permite considerar que la criatura concebida no alcanza aún la categoría de "embrión" al no haber transcurrido 14 días desde la fecundación. La misma diversidad de criterios no coincidentes entre sí para justificar la arbitrariedad de este plazo: que se trata del tiempo que demora la implantación del huevo en el útero materno, que no ha surgido aún la cresta neural o línea primitiva que desarrolla el sistema nervioso, que hasta ese momento es posible que el huevo se divida o se fusione con otros, lo que negaría su individualidad, es bastante reveladora de que ninguno de ellos es suficientemente fuerte para justificar la desprotección e indefensión en que queda la criatura concebida en sus dos primeras semanas de vida. No explican qué cambio cualitativo o esencial se produciría al día $15^{\circ}$ que determinaría que lo que era un organismo, aun no humano, pase a convertirse en un ser humano protegible e inviolable en sus derechos.

Debe tenerse en cuenta, por lo demás, que con los sistemas de criopreservación en frío el plazo de las dos semanas es ampliable a voluntad por los investigadores y técnicos, que pasan a tener un dominio absoluto sobre el momento en que este "organismo" pasa a convertirse en "embrión" o criatura humana protegida legalmente.

El concepto de "pre-embryo" fue acogido por primera vez por el informe de la llamada Comisión Warnock (Gran Bretaña, 1984). Posteriormente ha sido "canonizado" legalmente por la ley española de 1988. y por la ley inglesa de 1990. Cfr. MULKAY, MICHAEL, "The triumph of the pre-embryo: interpretations of the human embryo in Parliamentary debate over embryo research", en Social Studies of Science, vol. 24, 1994, pp. 611 y ss. 
Todo indica por el contrario que si el huevo fecundado tiene la potencialidad por sí mismo de llegar a convertirse en una criatura humana capaz de nacer y vivir, es porque es una vida humana personalizada desde su primer origen. Como afirmaba TERTULIANO, ya en los primeros siglos del cristianismo: "ya es un hombre aquél que lo será" $"$.

\section{El problema de la individualidad: división y fusión gemelar}

La eventual posibilidad de que el huevo fecundado pueda dividirse y dar lugar a gemelos, o la más remota de que dos huevos puedan fusionarse y dar origen a un único ser (fusión gemelar), no alcanzan a contradecir la individualidad del embrión. Por una parte, se hace ver que el carácter individual no supone la indivisibilidad: lo individual se opone a lo universal (la casa, el hombre); no a lo divisible. Por otro lado, es aún muy poco lo que se sabe sobre estos procesos biológicos, en todo caso excepcionales, como para extraer la conclusión, de consecuencias tan rotundas, de la falta de individualidad humana del cigoto.

\section{¿Y el espíritu? El problema de la infusión del alma}

Más compleja es la pregunta sobre el momento preciso en que el nasciturus alcanza aquél principio espiritual que constituye lo propiamente humano, aquello que llamamos el "alma racional". Es sabido que Aristóteles, y luego Tomás de Aquino, llegaron a la conclusión de que el alma no podía provenir de la misma materia, (Aristóteles dirá que viene "de afuera"; Tomás la referirá a la directa intervención divina que crea cada alma individual), y sentaron el principio de que la unión sucedía cuando el organismo estaba en condiciones de recibir el elemento espiritual. Ambos, siguiendo las antiguas teorías sobre la biología de la reproducción, sostuvieron que ello no ocurría inmediatamente en la concepción, sino más adelante (entre 40 y 90 días según si se trataba de varones o mujeres) ${ }^{8}$. Debe tenerse en cuenta que esta doctrina de la "infusión retardada del alma" ha sido discutida entre teólogos y moralistas, pero sin afectar para nada la unánime reprobación que desde los primeros tiempos ha hecho la Iglesia Católica del aborto procurado.

Aunque el instante preciso en que el alma se une al cuerpo organizado es una cuestión que sigue abierta en la teología, ya que el Magisterio de la Iglesia no ha estimado oportuno pronunciarse al respecto, debe tenerse en cuenta que para efectos morales y jurídicos la simple duda sobre ese momento preciso impele a respetar al concebido como si fuera una persona desde el mismo instante de su origen biológico: "está en juego algo tan importante que, desde el punto de vista de la obligación moral, bastaría la sola probabilidad de encontrarse ante una persona para justificar la más rotunda prohibición de cualquier intervención destinada a eliminar un embrión humano" .

\footnotetext{
${ }^{7}$ Apologeticum, IX, 8: CSEL 69, 24.

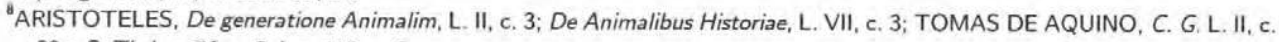
89 y S. Th. I, q. 76, a. 3; I, q. 118 , a. 2.

9 JUAN PABLO II, Evangelium Vitae. Carta Encíclica sobre el valor y el carácter inviolable de la vida humana, de 25 de marzo de 1995, $n^{2} 60$. Por otra parte, hay razones fundadas para sostener que los actuales conocimientos que poseemos sobre la realidad
} 


\section{Un argumento de última hora: la "singamia" como momento relevante}

La misma razón anterior debiera aplicarse para rechazar el criterio de aquellos que sostienen que el comienzo de la vida individual debe atribuirse a la fusión de los pronúcleos masculino y femenino, y a la alineación del material genético anterior a la primera división del huevo (la llamada "singamia"). Así lo plantea el proyecto de ley que regula la fertilización asistida redactado por la Comisión de Salud del Senado: según el texto "se entiende por concepción el momento de la singamia, esto es, cuando el material genético del varón y la mujer se integran y complementan en un núcleo único" (art. 3 , inc. $\left.2^{\circ}\right)^{10}$. Nuevamente estamos ante un intento de excluir al embrión, en algún momento de su desarrollo, de la cobertura jurídica que debiera otorgarse a todos los seres humanos (contando con que la criopreservación permite el alargamiento indefinido y discrecional de la etapa excluida ${ }^{11}$ ), sin que se explique la razón ontológica de la frontera que se quiere poner entre lo no humano y lo humano. Ya antes de la fusión de los pronúcleos, desde la misma unión de las membranas gaméticas (al penetrar el espermio en el óvulo) existe un sistema celular completo que contiene en sí la fuerza para crecer y desarrollarse por sí mismo, ¿por qué negarle el carácter de individuo humano por el solo hecho de que no se ha producido un fenómeno (el alineamiento cromosómico) que sólo es uno de los muchos que transcurrirán durante todo el proceso de gestación? ${ }^{12}$

\section{Algunas propuestas alternativas a la admisión de personalidad del embrión}

No obstante que el reconocer la titularidad subjetiva del embrión tanto en el plano personal como patrimonial parece ser la explicación más coherente con su realidad biológica, los fuertes intereses conectados con la posibilidad de manipular y destruir embriones humanos determinan que no exista una voluntad generalizada para admitirla en los círculos políticos y científicos. Por cierto, prácticamente nadie afirma al menos públicamente- que el embrión sea una cosa manejable y destruible a voluntad. Pero se buscan soluciones alternativas que, junto con ofrecer un cierto marco de

biológica del concebido propician la necesidad de que el alma intelectiva se encuentre presente desde los primeros instantes. Cfr. UGARTE GODOY, JOSE JOAQUIN, "Comienzo de la existencia humana o momento a partir del cual el embrión es persona humana", en La vida ante el Derecho, P. Universidad Católica de Chile, Santiago, 1996, pp. 43 y ss.

${ }^{10}$ Como se ha hecho ver, el texto legal es biológicamente incorrecto ya que en los mamíferos nunca se llega a producir la fusión del material genético en un sólo núcleo. Después del alineamiento del material genético, se produce la división del huevo, dando lugar al blastómero.

${ }^{11}$ En el extranjero se reconoce sin problemas la funcionalidad práctica que a los efectos de la criopreservación reporta el concepto de "célula en estado de pronúcleo". Señala GAFO, JAVIER, 10 Palabras clave en Bioética, Edit. Verbo Divino, Navarra, 1993, p. 199, que hoy se está realizando frecuentemente la criopreservación en la fase de "pre-cigoto", esto es, antes de la unión de los pronúcleos, ya que: "Esta fase es muy estable y facilita el proceso de criopreservación".

12 En el debate público chileno, se ha invocado que la Instrucción Vaticana "Donum Vitae" sobre el respeto de la vida humana naciente y la dignidad de la procreación, de 1987, en su versión española, contiene una apostilla entre las notas 25 y 26 que define el cigoto como "la célula resultante de la fusión de los núcleos de los dos gametos". Pero se trata evidentemente de un error de traducción, ya que en el texto oficial, en latín, puede leerse "zygotum est cellula orta a fusione duorum gametum" (AAS LXXX, 1988, p. 78), es decir, "el cigoto es la célula resultante de la fusión de los dos gametos". EI Prefecto de la Sagrada Congregación para la Doctrina de la Fe, Cardenal Ratzinger, ha aclarado el punto en carta de fecha 16 de julio de 1996 dirigida a los Presidentes de las Conferencias Episcopales, en la que pide que el texto de la Instrucción sea traducido siguiendo "la edición típica latina así como hacerlo conocer al público y velar para que sea insertado en una eventual reedición del documento". 
protección legal al nasciturus, dejen abierta la puerta para su utilización e incluso su destrucción, en ciertos casos en los que ello pueda resultar conveniente.

Se señala entonces que el embrión no tendría subjetividad jurídica (no es persona), pero que sería una expresión del valor "vida humana" que debe ser protegido como un bien jurídico especialmente importante. Incluso se ha planteado que el embrión humano debería gozar de una protección similar a la otorgada a los bienes declarados "patrimonio de la humanidad", para que, de esta manera, se prohiban y castiguen los abusos en su manejo y tratamiento.

Por buenas que sean las intenciones de explicar y otorgar una protección al nasciturus sobre la base de estas teorías, pensamos que ellas son insuficientes, pues siguen reteniendo al embrión en el ámbito de las cosas, valiosas jurídicamente si se quiere, pero cosas al fin. $Y$ esto tiene relevancia, pues cuando entran en conflicto intereses o derechos humanos (como el de la madre a no soportar el embarazo) con la "cosa", aunque valiosa, en que se ha convertido la vida humana del embrión, encuentra natural aplicación el refrán de que "el hilo se corta por lo más delgado". Aquí lo más delgado es el "bien-embrión" frente a la "persona-madre" y sus derechos. Y lo proprio cabe decir frente al enfermo de parkinson que necesita un implante de células cerebrales de embriones, o ante la pareja que pretende solucionar su infertilidad a costa del desecho o deceso de embriones en la aplicación de técnicas de fertilización asistida.

Otros autores han ido más allá en esta búsqueda de una explicación razonable y sostienen que el nasciturus quedaría comprendido dentro de la categoría general de "sujeto de derecho" como entidad diferente a la "persona natural". El embrión sería sujeto de derechos pero no propiamente persona. Es claro que al final la cuestión puede ser sólo semántica, y dependerá de qué contenido le atribuimos a los términos "sujeto de derechos" y "persona". Pero, habiéndose universalizado el uso de la palabra "persona" para designar la dignidad y la inviolabilidad de todo ser humano concreto, así como el derecho a que la ley le proteja de un modo máximo, parece inconveniente desguarnecer al embrión humano de esa denominación, toda vez que ello inevitablemente indicará que éste no tiene acceso al mismo tratamiento protector con que cuenta el ser humano ya nacido.

Nos parece que la solución de que el ser humano debe ser tratado como persona desde el mismo inicio de su desarrollo y hasta el preciso instante de su muerte, es la única que permite explicar tanto su capacidad patrimonial como su titularidad sobre derechos personales, en especial el de mantener su vida y el de conservar la salud e integridad física.

\section{El status del embrión en el ordenamiento jurídico chileno}

\section{La personalidad del embrión en la ley civil}

Después de analizar en profundidad nuestro ordenamiento jurídico debe constatarse que hay un claro y firme reconocimiento de la personalidad del embrión, al que la ley civil gusta denominar como "criatura que ésta por nacer". Esta conclusión parece estar en contra del texto del art. 74 del Código Civil que expresamente señala que "la existencia legal de toda persona principia al nacer, esto es, al separarse 
completamente de su madre", de modo que la criatura que muere en el vientre materno o antes de esa separación "se reputará no haber existido jamás".

Pero el tenor literal del art. 74, a nuestro juicio, ha sido sobredimensionado y aplicado fuera de su órbita natural por la doctrina común, llevándola a proclamar como dogma incuestionable que la ley civil no reconoce la personalidad del nasciturus ${ }^{13}$

Esta afirmación no tiene en cuenta que el mismo Código Civil contiene numerosas disposiciones que claramente demuestran que la ley civil reconoce y protege la personalidad del que está por nacer:

$\left.1^{\circ}\right)$ Por de pronto, se le incluye claramente en la definición de persona que el Código Civil formula en el poco considerado art. 55: "Son personas todos los individuos de la especie humana, cualquiera que sea su edad...". El embrión es individuo y pertenece a la especie humana, por lo cual, con prescindencia de su desarrollo cronológico (edad), debe ser considerado como persona.

$2^{\circ}$ ) Congruentemente con lo anterior se declara solemnemente que "la ley protege la vida del que está por nacer" (art, $75 \mathrm{CC}$ ). Adviértase que la expresión "el que está por nacer" evoca claramente la personalidad: se trata de "alguien", no de "algo".

$3^{\circ}$ ) Se atribuyen facultades amplísimas al juez para adoptar, de oficio o a petición de cualquiera persona, "todas las providencias que le parezcan convenientes para proteger la existencia del no nacido, siempre que crea que de algún modo peligra" (art. 75 CC). Esta norma debiera relacionarse con el art. 26, № 7 de la ley № 16.618 , que permite a los jueces de menores adoptar medidas de protección cuando un menor de edad "se encontrare en peligro material o moral", y también con las disposiciones que castigan penalmente el aborto provocado (arts. 342 y siguientes del Código Penal) y prohiben toda acción que tenga como fin directo el aborto (119 del Código Sanitario).

$\left.4^{\circ}\right)$ Se determina que todo castigo a la madre por el cual pudiera peligrar la vida - la salud de la criatura que tiene en su seno, debe diferirse hasta después de su nacimiento (art. 75 , inc. $2^{\circ}, \mathrm{CC}$ ). Por lo que, en todo caso, debe suspenderse la aplicación de la pena de muerte (art. 85 del Código Penal).

$\left.5^{\circ}\right)$ Se declara la protección que el Estado debe proporcionar al hijo que está por nacer. El Código Sanitario dispone que "Toda mujer durante el embarazo y hasta el sexto mes del nacimiento del hijo, y el niño, tendrán derecho a la protección y vigilancia del Estado por intermedio de las instituciones que correspondan", de modo que, "La tuición del Estado comprenderá la higiene y asistencia social tanto de la madre como del hijo" (art. 16).

\footnotetext{
" En justicia debemos reconocer que nuestro pensamiento en esta materia ha sufrido una cierta evolución. En un primer momento no estimábamos posible afirmar con seguridad el reconocimiento positivo de la personalidad civil del concebido, por lo cual propiciábamos que se revisaran aquellas normas civiles que, como el art. 74 del Código, parecían negar esa calidad al embrión. No obstante, ya en ese momento hacíamos ver la necesidad de "revisar los conceptos dogmáticos tradicionales, y ahondar en el concepto de persona natural que da el Código civil chileno" (CORRAL TALCIANI, H., ob. cit., p. 47, nt. 46). Es la labor que esperamos estar llevando a cabo en exposiciones como ésta. Recientemente, LARRAIN RIOS, HERNAN, Lecciones de Derecho Civil, Edit. Jurídica de Chile, Santiago, 1994, pp. 132 y ss, ha sostenido que el Código Civil reconoce la "personalidad natural" del concebido.
} 
$\left.6^{\circ}\right)$ Se protegen igualmente los derechos patrimoniales del nasciturus: todos los derechos que se le defieren a la criatura permanecen en suspenso, y si llega a nacer entra en el goce de ellos como si hubiese estado ya nacido al momento en que se le defirieron (art. 77 CC).

$\left.7^{\circ}\right)$ Por tal razón, el nasciturus goza de capacidad para suceder por causa de muerte (art. 962 CC), y para recibir donaciones (art. 1390 CC).

$\left.8^{\circ}\right)$ Además, la ley provee un administrador para los derechos que se le defieran mientras se encuentra en gestación, concediendo al padre o a la madre legítima la patria potestad sobre el que está por nacer (art. 240 , inciso $2^{\circ}$ CC), y, a falta de éstos, posibilitando el nombramiento de un curador de bienes (ad ventris) (arts. 485 y siguientes (C).

$\left.9^{\circ}\right)$ De los derechos patrimoniales que puedan corresponder al hijo póstumo en gestación puede la madre pedir lo necesario para su subsistencia y para el parto. Así lo dispone expresamente el art. 199 del Código Civil. En similar sentido, la Ley de Abandono de Familia y Pago de Pensiones Alimenticias extiende a la madre el derecho de alimentos cuando éste deba corresponder al hijo que está por nacer (art. 4 Ley № 14.908, de 1962).

10) Por último, aunque el art. 74 del Código Civil utiliza la cruda expresión para el niño que muere antes de nacer: "se reputará no haber existido jamás", la Ley de Registro Civil, (si bien omite por razones prácticas las inscripciones de nacimiento y defunción), contempla la necesidad de dar sepultura a los restos de la criatura no nacida en los cementerios destinados a cadáveres humanos, y ordena el otorgamiento del respectivo pase de sepultación (art. 49 de la Ley de Registro Civil) ${ }^{14}$.

\section{El problema del art. 74: "la existencia legal principia al nacer..."}

Expuestas las normas anteriores, se impone una interpretación finalista y contextualizada del precepto del art. 74 , que en su tenor literal parece postergar la personalidad del embrión hasta cuando haya ocurrido el nacimiento, esto es, cuando la criatura se haya separado completamente de la madre y sobrevivido algún momento a esa separación. Yendo más allá de las expresiones literales del precepto, queda claro que el Codificador no ha querido otra cosa que fijar con certeza el punto en el que se consolidan definitivamente las relaciones patrimoniales surgidas en favor del que está por nacer durante su gestación, pero que en ningún caso ha pretendido negar al nasciturus su cualidad de sujeto de derechos.

Resulta manifiesto que la fórmula del art. 74, en relación con la disposición del art. 77 del Código Civil, no es más que un medio técnico destinado a condicionar la capacidad patrimonial del embrión a su nacimiento, evitando de esta forma desplazamientos inciertos de la propiedad. La norma nos viene a decir que, en caso de muerte antes del nacimiento, el feto no es considerado causante para efectos sucesorios, articulando la ley una ficción (que ella misma reconoce como contraria a la

\footnotetext{
${ }^{14}$ En contra de la dignidad de los restos del no nacido se revela el D. S. № 240, del Ministerio de Salud, de 3 de junio de 1983 , Reglamento del Título IX del Código Sanitario, cuando dispone que son admisibles las donaciones de "todo producto de la concepción que no llegue a nacer vivo", las que se perfeccionan por la sola voluntad del donante (art. 17). Se trata de una disposición de un tenor muy desafortunado y que no se muestra congruente con el espíritu general de nuestra legislación.
} 
realidad de las cosas) de que la criatura no ha llegado a la existencia ("se reputará" dice el Código no haber existido). Se trata, por tanto, de un desconocimiento a posteriori de la capacidad patrimonial, que no puede considerarse atentatorio para la dignidad del embrión ya que ella se verifica cuando éste ya no tiene existencia. Nadie podría sostener que con ello se le desconoce injustamente el derecho de transmitir sus propios bienes: no resulta razonable conservar ese derecho respecto de alguien que no podrá tener nunca la posibilidad de ejercerlo.

Otra razón práctica para seguir el mismo criterio la da GUZMAN BRITO, explicando el Derecho romano: "la razón es clara: nacida muerta una criatura, no siempre es posible saber en qué momento murió ni, por ende, si alcanzó o no a adquirir un patrimonio (hereditario) y a causar o no su propia herencia" ${ }^{15}$. Pensamos que el argumento mantiene su vigencia en el Derecho patrimonial moderno.

\section{La personalidad del embrión en la Constitución}

Si revisamos la cuestión desde el punto de vista constitucional, la subjetividad jurídica del embrión debe afirmase con mayor fuerza. La Constitución Política señala, en su artículo 19, que ella asegura a "todas las personas", ciertos derechos fundamentales entre los cuales menciona el derecho a la vida del que está por nacer (art. 19, № 1). De este modo, ha previsto la aplicabilidad del recurso de protección para restablecer el imperio del Derecho en caso de que ese derecho sufra privación. perturbación o amenaza por actos u omisiones arbitrarias o ilegales (art. 20 Const.)

Se ha sostenido que la referencia del № 1 del art. 19 de la Constitución no implica un reconocimiento de la personalidad del embrión humano, por cuanto se observa una clara diferencia entre el derecho a la vida y a la integridad física que se reconoce para toda persona en el inciso primero del $N^{\circ} 1$, y la alusión del inc, $2^{\circ}$ al concebido, para el cual esa protección no sería asumida directamente por la Constitución sino encargada a la prudencia del legislador. De esta manera, debería ser la ley quien determinara la cobertura protectora de la vida del que está por nacer y sus posibles excepciones. Se invocan las discusiones sobre la procedencia del aborto terapéutico de que dan cuenta las Actas de la Comisión Constituyente.

Por otro lado, se observa que la norma (constitucional y civil) sólo se referíra a las criaturas que están en el vientre materno (embriones implantados), y no a los huevos fecundados y desarrollados in vitro, en medio extracorpóreo. Respecto de estos últimos no podría decirse propiamente que "están por nacer", esto es, en vías de nacer $^{16}$.

Nos parecen equivocados ambos planteamientos. Comienzo por refutar el segundo: no cabe en esta materia una interpretación tan literalista que no admita que la fórmula del que está por nacer es una expresión semántica, hermosa y hasta poética, pero que se refiere a todas las criaturas humanas vivas no nacidas, independientemente del medio físico en el que se encuentren. Se trata, no del que está en vías de nacer, sino

\footnotetext{
${ }^{15}$ GUZMAN BRITO, A., ob. cit., t. I, § 54, p. 277.

${ }^{16}$ Cfr. FIGUEROA YAÑEZ, GONZALO, Persona, pareja y familia, Edit. Jurídica de Chile, Santiago, 1995, p. 54, quien sostiene que el art. 75 del Código protege sólo a los embriones ya implantados en el seno de la madre. Los embriones concebidos in vitro no pertenecerían ni siquiera a la categoría de "los que están por nacer".
} 
del que está llamado, por su propia conformación natural, a nacer; (de lo contrario, y extremando las cosas más de alguno llegaría a sostener que sólo el feto ya formado y viable sería una criatura que está realmente "por nacer").

Respecto de la menor intensidad de protección que quiere deducirse de la incorporación de la norma específica referida a la vida del nasciturus después de la consagración general del derecho a la vida en el art. 19, № 1 de la Constitución, debe partirse por destacar que si ello fuera correcto, la intención de los redactores, que fue indudablemente el enfatizar que la protección de la vida incluía al concebido, hubiera tenido resultados totalmente inversos. Mucho más lógico es pensar que la vida de todos los seres humanos es protegida de igual manera por la Constitución, y que la referencia especial a los concebidos es más bien un mandato dirigido al legislador para que dicte normas legales especiales que hagan realidad esa protección respecto de los nascituri, atendidas las amenazas que los tiempos actuales conocen en su contra. Adviértase que la Constitución no cosifica al nasciturus y que implícitamente reconoce su subjetividad: habla de "el que" está por nacer, y no de "lo que" está por nacer.

Por lo demás esta norma debe ser interpretada en el contexto y según el espíritu de la Constitución. De esta manera, ha de relacionarse con el art. 1ำ que declara que el Estado está al servicio de la persona humana, y con el art. 5ำ que reconoce los derechos esenciales que derivan de la naturaleza humana, siendo claro que el embrión humano cuenta con tales derechos ${ }^{17}$.

\section{La cuestión en los tratados internacionales}

Recordemos que el inc. $2^{\circ}$ del art. 5 de la Constitución establece el deber de los órganos del Estado de respetar y promover los derechos esenciales de la naturaleza humana garantizados por la Constitución y por "los tratados internacionales ratificados por Chile y que se encuentren vigentes". Pues bien, en esta materia ha de recibir aplicación la Convención Americana sobre Derechos Humanos, llamada "Pacto de San José de Costa Rica" que declara solemnemente que "Toda persona tiene derecho a que se respete su vida" y que "este derecho estará protegido por la ley, y en general, a partir del momento de la concepción" (art. 4.1).

La expresión "en general" no debe interpretarse en el sentido de privar de fuerza al texto admitiendo que las leyes nacionales puedan establecer excepciones a la protección de la vida desde la concepción. Sería absurdo proclamar un derecho tan esencial dejando libertad para establecer toda clase de excepciones que lo desconozcan. La locución ha querido, por el contrario, enfatizar que la protección de la vida por nacer rige para todos: es "general", y no sólo para algunos ${ }^{18}$.

Cabe citar también en este sentido la Convención sobre los Derechos del Niño, suscrita por Chile el 26 de enero de 1990 (D. Oficial de 27 de septiembre de 1990). La

\footnotetext{
${ }^{17} \mathrm{Cfr}$. PRECHT PIZARRO, JORGE, "La administración del Estado al servicio de la persona en gestación", en Revista de Derecho Público, N57/58, 1995, pp. 199 y ss.

${ }^{18}$ Como bien sostiene un comentador argentino: "La expresión simplemente aclara, hasta enfatizando, que la protección de la ley comienza con el inicio de la concepción, momento desde el cual se reconoce el principio de la vida humana. De esta manera, la expresión 'en general' - en el contexto enfático de la oración- indica 'en todos los casos', o 'en igualdad de condiciones para todos los casos'" (BARRA, RODOLFO CARLOS, La protección constitucional del derecho a la vida, Abeledo-Perrot, B. Aires, 1996, p. 60)
} 
Convención declara enfáticamente que, para sus efectos, se "entiende por niño todo ser humano menor de dieciocho años de edad... " (art. 1). Esta definición comprende a los nascituri ya que, según la misma Convención, "el niño por su falta de madurez física y mental, necesita protección y cuidado especiales, incluso la debida protección legal, tanto antes como después del nacimiento" (preámbulo).

En conclusión, tanto desde el punto de vista constitucional, como de los tratados internacionales sobre derechos fundamentales, como en el plano de la simple regulación legal, en nuestro sistema jurídico el embrión humano, desde el origen de su vida, goza de la calidad y status jurídico de persona, y como tal es acreedor de la protección completa del ordenamiento jurídico y de los órganos del Estado. Cuenta también con la capacidad patrimonial y la titularidad de los derechos patrimoniales que se le defieran, aunque sujetos a consolidarse definitivamente una vez que ocurra el nacimiento.

\section{Los atisbos en la jurisprudencia judicial y administrativa}

Aunque no son muy numerosas, ni tampoco muy explícitas, existen ya unas cuantas sentencias de los Tribunales Ordinarios, que se han pronunciado claramente sobre la necesidad de proteger la vida del que está por nacer. Está firmemente establecido que el recurso de protección al que se refiere el art. 20 de la Constitución puede ser interpuesto en favor del nasciturus ${ }^{19}$.

Así, por ejemplo, el fallo de la Corte de Apelaciones de Santiago, de 29 de septiembre de 1989 (GJ № 111, p. 33), estableció que la negativa ilegal a tramitar una licencia maternal causaba daño a la salud de la madre y constituía un peligro para la vida del que está por nacer. La misma Corte, ante el recurso de protección interpuesto por el Director del Servicio de Salud Metropolitano en favor de la vida del hijo en gestación de una paciente que, por razones religiosas, se negaba a consentir en una transfusión sanguínea que se preveía como necesaria para proceder sin peligro a una operación cesárea, ordenó como medida cautelar que se adoptaran desde ya todas las medidas tendientes a resguardar y preservar la vida del que está por nacer y su madre (RDJ t. 88 , sec. $5^{\mathrm{a}}$, p. 340$)^{20}$.

Por su parte, la Contraloría General de la República ha dictaminado que el Servicio Nacional de Menores (SENAME) tiene competencia para celebrar convenios de financiamiento de programas de ayuda a los nonatos (Dictamen № 14.525, de $1992)^{21}$. También ha resuelto favorablemente la cuestión sobre si los niños en gestación, que fueron privados de la vida como víctimas de violaciones de derechos humanos, eran personas causantes de los beneficios establecidos por la Ley № 19.123 (Dictamen № 25.403, de 21 de agosto de 1995) 22. $^{22}$

\footnotetext{
${ }^{19}$ Cfr. SOTO KLOSS, EDUARDO, "Derecho a la vida y recurso de protección", en RDJ t. 81, sec. Derecho, p. 60.

${ }^{20}$ La sentencia finalmente tuvo que rechazar el recurso por haber nacido en el intertanto el niño, y haber así desaparecido el riesgo al derecho a la vida del que estaba por nacer. Un comentario al fallo es el artículo de SOTO KLOSS, EDUARDO, "EI Derecho a la vida y la noción de persona en la Constitución", en $R D J \mathrm{t} .88$, sec. Derecho, pp. 55 y ss.

${ }^{21}$ El dictamen puede verse, seguido de un comentario nuestro, en la Revista Chilena de Derecho, vol. 19, №3, pp. 603 y ss.

22 Sostuvo la Contraloría en este importante pronunciamiento: "Así pues, y como quiera que acorde con el artículo $5^{2}$ de la Carta Fundamental es deber de los "rganos del Estado respetar y promover los derechos que emanan de tratados internacionales ratificados por Chile que se encuentrtan vigentes -cuyo es el caso de la aludida Convención Americana de Derecho Humanos-el
} 


\section{Sentido del Derecho y personalidad del embrión humano}

Si nos atrevemos a sostener de un modo coherente y consistente que el embrión, desde el mismo momento en que es concebido, es un individuo que pertenece a la especie humana, no podremos rehuir la conclusión de que debe ser tratado jurídicamente como son tratadas las personas ya nacidas, con la misma dignidad y especialmente con el carácter inviolable e indisponible que otorgamos al concepto de personalidad. No resultará admisible ninguna forma de "cosificación" del nasciturus que rebaje o menosprecie esa condición, cualesquiera sea la calidad moral o utilidad de los fines que se invoque para privarlo de su existencia o distorsionar su desarrollo natural.

De este modo, las conductas que tengan por fin la destrucción de embriones, como la utilización de dispositivos intrauterinos microabortivos o la expulsión provocada del feto del seno materno, deben ser considerados jurídicamente ilícitas e incluso penalizables en las condiciones que determine la ley. La mayor o menor libertad de las personas que incurren en estos hechos (la mujer que consiente en un aborto por presiones angustiosas) podrá ser considerada en concreto, caso a caso, para determinar su culpabilidad personal o la graduación de la pena, pero no como un elemento objetivo que transforme en legal o lícita una conducta que, en el fondo, no es menos que el asesinato de un inocente que se encuentra en la más absoluta imposibilidad de defenderse.

Por lo mismo, el deseo de tener hijos o de remediar la infertilidad no puede llevarnos a considerar tolerable la destrucción de embriones, o su manejo como material desechable para conseguir esas finalidades, en sí mismas comprensibles y meritorias. Es claro que será ilegítimo todo desecho de embriones sobrantes, realizado al fecundarse varios huevos de una mujer para luego implantarle solo aquellos que parecen más viables. El descarte embrionario favorece la eugenesia, y contradice palmariamente la dignidad de estos diminutos e indefensos seres humanos. Lo mismo ha de señalarse respecto de la experimentación en embriones o de la utilización de sus tejidos o células en el tratamiento terapéutico de enfermedades de terceros adultos.

Aunque la técnica de la criopreservación surgió como alternativa al descarte embrionario que exigen normalmente los procedimientos de fertilización asistida, tampoco puede considerarse compatible con la condición humana de los embriones, ya que se termina por considerarles "material de depósito", y resultan expuestos a un gravísimo riesgo de muerte (sólo un reducido porcentaje sobrevive al descongelamiento). La criopreservación, por lo demás, ha demostrado su inoperancia para evitar la destrucción de los embriones sobrantes. La masacre legal de más de 3.000 embriones congelados no reclamados, llevada a cabo en Inglaterra durante 1996. prueba que el método del congelamiento conduce a la larga a los mismos resultados mortíferos.

En Chile los médicos que públicamente llevan a cabo técnicas de fertilización asistida reivindican la legitimidad del procedimiento por el cual se fecundan varios óvulos $(3 \circ 4)$, pero en que todos los embriones resultantes son transferidos a los órganos de la mujer receptora, la que desde ya acepta la posibilidad de un embarazo

nonato debe ser considerado como persona para los efectos en comento...". Cfr. PRECHT, J., ob, cit., p. 206. 
múltiple. Nos parece extremadamente discutible tanto la moralidad como la licitud de esta modalidad. En primer lugar, porque va en contra de la salud de la madre (derecho indisponible para ella), la que necesariamente se pone en peligro con los mayores riesgos comprobados que presenta una gestación múltiple. En segundo término, porque nuevamente los embriones transferidos, (atendidos los escasos resultados exitosos que exhibe esta técnica), son expuestos a una situación de tan extremado peligro para su vida, que el método no puede ser justificado por el interés de la pareja de tener un hijo. Nadie admitiría que varias personas adultas fueran colocadas en una situación, (por ejemplo, un viaje interplanetario o la prueba de una droga de efectos desconocidos), en que haya absoluta seguridad de que morirán todos, menos uno. $Y$ eso que estas personas podrían al menos consentir en exponer su vida, lo que no sucede con los embriones que son traídos al mundo para jugar esa suerte de "ruleta rusa" sin que nadie les haya preguntado nada ${ }^{23}$.

Es una paradoja de nuestro tiempo, quizá la más reveladora de las mentalidades culturales imperantes, el que hayamos avanzado tanto en el reconocimiento de derechos patrimoniales al embrión humano, y que hayamos, en cambio, retrocedido a las épocas más primitivas respecto de su protección personal. Con razón se ha dicho que nuestro tiempo pretende reconocer al nasciturus todos los derechos, menos el de vivir para disfrutarlos.

Puede a veces esto parecer una disquisición técnico-jurídica, un problema de menor entidad, o quizá una cuestión de corte ético-sociológico, en el que el Derecho puede tomar palco y esperar como simple espectador el último acto del drama. Me parece que un planteamiento como ése implica renunciar al Derecho como ciencia de lo justo y de lo injusto, como principal defensor de las personas y especialmente de las más débiles e indefensas. En la cuestión de los derechos del embrión está un gran desafío para el jurista de hoy, está en el fondo la cuestión del sentido del Derecho y de la justicia.

Si no somos capaces de reconocer en cada ser humano una persona semejante a cada uno de nosotros, y por tanto digna de respeto en cualquier circunstancia, con prescindencia de si nos guste o no su apariencia o su estilo de vida, de si es más o menos útil para la sociedad, de si su presencia incomoda o no a los demás, etc, etc; si no somos capaces de esto, el Derecho abdicará de su sentido más profundo, y también

\footnotetext{
" Se arguye en favor de este procedimiento que el médico no interviene en el proceso de anidación de los embriones transferidos, de modo que allí la pérdida embrionaria viene determinada por la acción de la naturaleza, al igual que lo que sucede en los abortos espontáneos (Cfr. ZEGERS HOCHSCHILD, FERNANDO, "Reproducción asistida en Chile. Consideraciones médicas e implicancias ético-legales", en El Mercurio, 16 de marzo de 1997, E-24). Pero el argumento no parece sustentable ya que el hecho de que ocurran muertes por hechos naturales desgraciados no puede autorizar que se reproduzcan las mismas circunstancias pero ahora con intervención directa de la voluntad y la responsabilidad humanas. Como expone MONGE. FERNANDO, Persona humana y procreación artificial, libros mc, Madrid, 1988, p. 94, "la naturalidad de los terremotos no faculta a los hombres a hacer ensayos controlados con cobayas humanas, aun con el buen fin de mejorar las condiciones antisísmicas urbanas. Pues, al reproducir voluntariamente un mal, los actores son causa directa de la catástrofe, aunque sea controlada, y de la muerte de personas si se diera".
} 
cualquiera de nosotros estará expuesto a los abusos más inhumanos si el día de mañana, por las circunstancias que sean, los demás comienzan a valorarlo como bien "valioso" pero ya no como persona. Como sostenía ROMANO GUARDINI "el Derecho o existe absolutamente para todos sin excepción o no existe" ${ }^{24}$.

Si los que están por nacer no tienen derecho a la vida, tampoco ninguno de nosotros puede reclamar que se le reconozca ese derecho. Si el embrión no es persona me atrevo a decir- en realidad ningún ser humano lo es. 